\title{
Comparative study of minimal fresh gas flow used in Lack-Plus and Lack's circuit in spontaneously breathing anesthetized adults
}

This article was published in the following Dove Press journal:

Medical Devices: Evidence and Research

8 November 2016

Number of times this article has been viewed

\section{Sunchai Theerapongpakdee Thepakorn Sathitkarnmanee Sirirat Tribuddharat \\ Siwalai Sucher \\ Maneerat Thananun Duangthida Nonlhaopol}

Department of Anesthesiology, Faculty of Medicine, Khon Kaen University, Khon Kaen, Thailand
Correspondence: Thepakorn Sathitkarnmanee

Department of Anesthesiology, Faculty of Medicine, Khon Kaen University, 123 Mitrapap Road, Ampur Muang, Khon Kaen 40002, Thailand

Email thepakorns@gmail.com
Background: The Lack's circuit is a co-axial Mapleson A breathing system commonly used in spontaneously breathing anesthetized adults but still requires high fresh gas flow (FGF). The Lack-Plus circuit was invented with the advantage of lower FGF requirement. The authors compared the Lack-Plus and Lack's circuit for the minimal FGF requirement with no rebreathing in spontaneously breathing anesthetized adults.

Methods: This was a randomized crossover study. We enrolled 24 adult patients undergoing supine elective surgery, with a body mass index $\leq 30 \mathrm{~kg} / \mathrm{m}^{2}$ and an American Society of Anesthesiologists physical status I-II. They were randomly allocated to group 1 (LP-L) starting with Lack-Plus then switching to Lack's circuit or group 2 (L-LP) (with the reverse pattern). After induction and intubation, anesthesia was maintained with $50 \% \mathrm{~N}_{2} \mathrm{O} / \mathrm{O}_{2}$ and desflurane $(4 \%-6 \%)$ plus fentanyl titration to maintain an optimal respiratory rate between 10 and 16/min. Starting with the first circuit, all the patients were spontaneously breathing with a FGF of $4 \mathrm{~L} / \mathrm{min}$ for $10 \mathrm{~min}$, gradually decreased by $0.5 \mathrm{~L} / \mathrm{min}$ every $5 \mathrm{~min}$ until $\mathrm{FGF}$ was $2.5 \mathrm{~L} / \mathrm{min}$. End-tidal $\mathrm{CO}_{2}$, inspired minimum $\mathrm{CO}_{2}\left(\mathrm{ImCO}_{2}\right)$, mean arterial pressure, and oxygen saturation were recorded until rebreathing $\left(\mathrm{ImCO}_{2}>0 \mathrm{mmHg}\right.$ ) occurred. The alternate anesthesia breathing circuit was used and the measurements were repeated.

Results: The respective minimal FGF at the point of rebreathing for the Lack-Plus and Lack's circuit was $2.7 \pm 0.8$ and $3.3 \pm 0.5 \mathrm{~L} / \mathrm{min}$, respectively, $p<0.001$. At an FGF of $2.5 \mathrm{~L} / \mathrm{min}$, the respective $\mathrm{ImCO}_{2}$ was $1.5 \pm 2.0$ and $4.2 \pm 2.6 \mathrm{mmHg}$, respectively, $p<0.001$.

Conclusion: The Lack-Plus circuit can be used safely and effectively, and it requires less FGF than Lack's circuit in spontaneously breathing anesthetized adults.

Keywords: spontaneous breathing, anesthesia, non-rebreathing anesthetic circuit, modified Mapleson A breathing system, coaxial breathing system, rebreathing

\section{Introduction}

The Lack's circuit (or modified co-axial Mapleson A breathing system) is commonly used in spontaneously breathing anesthetized adults. It does not contain a carbon dioxide absorber; thus, its performance relies on an adequate fresh gas flow (FGF) to prevent rebreathing. ${ }^{1}$ The Lack's circuit is the most efficient and economical system for spontaneous respiration in adults compared to the Magill's and Bain's circuits. ${ }^{1}$ It is compact, lightweight and portable, with additional convenient access to the exhaust (adjustable pressure limiting or APL valve), easy scavenging of polluting gases, and low expiratory resistance.

According to the philosophy on sustainable economics of Thailand's sovereign (His Majesty King Bhumibol), "Understanding, Accessibility and Development” represent 
the three rings for success. We thus invented the modified Lack's circuit for use in adult patients - aka the Lack-Plus circuit - using inexpensive and readily available materials in the operating room. ${ }^{2}$

The difference between the Lack and Lack-Plus circuits is that the Lack-Plus circuit has an additional intraluminal oneway valve on the inner expiratory tube situated proximal to the APL valve, which minimizes FGF, saves anesthetic gas, and decreases operating room pollution. The components include a $100 \mathrm{~mL}$ normal saline solution plastic bottle; a rubber glove; $1,3,10$, and $20 \mathrm{~mL}$ plastic syringes; a $22 \mathrm{~mm}$ internal diameter corrugated tube (outer reservoir tube); a $10 \mathrm{~mm}$ internal diameter hollow plastic tube (inner exhaust tube); a yellow hollow latex rubber tubes with connector for FGF outlet; and a 22 $\mathrm{mm}$ internal diameter three-way plastic connector (Figure 1).

\section{Objectives}

The aim of this clinical trial was to compare the Lack-Plus and Lack's circuit vis-à-vis minimal FGF requirements with no rebreathing in spontaneously breathing anesthetized adults.

\section{Materials and methods}

The Institutional Review Board of Khon Kaen University (KKU) approved the study (HE571249). All the patients provided written informed consent.

The current study was conducted at Srinagarind Hospital, Faculty of Medicine, KKU, Khon Kaen, Thailand. Between September and October 2014, 24 patients aged between 18 and 60 years with an American Society of Anesthesiologists (ASA) physical status I-II and body mass index $(\mathrm{BMI}) \leq 30 \mathrm{~kg} / \mathrm{m}^{2}$, scheduled for elective peripheral surgery in supine position under general anesthesia, were included in a randomized crossover study. Patients were excluded if they had a body temperature $>37.8^{\circ} \mathrm{C}$, a respiratory disease (COPD, asthma, chronic bronchitis), a cardiovascular disease, a contraindication to succinylcholine, or they refused surgery.

Immediately after the patients entered the operating room, eligible patients were randomly assigned to one of the following two arms:

1. LP-L: the Lack-Plus circuit was used first and then switched to the Lack's circuit or

2. L-LP: the Lack's circuit was used first and then switched to the Lack-Plus circuit

The multi-gas monitor used in this study was Philips IntelliVue MP30 with M1013A module (Philips MedizinSysteme Böblingen GmbH, Böblingen, Germany).

All the patients were given diazepam $0.1-0.2 \mathrm{mg} / \mathrm{kg}$ and paracetamol $10-15 \mathrm{mg} / \mathrm{kg}$ orally $1 \mathrm{~h}$ before transferring to the operating room. Baseline blood pressure, pulse, and oxygen saturation $\left(\mathrm{SpO}_{2}\right)$ were obtained by standard monitors. Anesthesia was induced with fentanyl $1-2 \mu \mathrm{g} / \mathrm{kg}$ and propofol $2-2.5 \mathrm{mg} / \mathrm{kg}$ IV. Then, each patient was intubated using succinylcholine $1-1.5 \mathrm{mg} / \mathrm{kg}$ IV. Anesthesia was maintained with FGF containing $50 \% \mathrm{~N}_{2} \mathrm{O} / \mathrm{O}_{2}$ in combination with desflurane $4 \%-6 \%$, adjusted to $1-1.2 \mathrm{MAC}$ anesthetic level to maintain normal vital signs. Fentanyl was titrated to ensure an optimal respiratory rate (RR; range, 10-16/min). All the patients were spontaneously breathing with FGF $4 \mathrm{~L} / \mathrm{min}$ at the start of each anesthetic breathing circuit. The authors waited for the depth of surgical anesthesia to be maintained for at least $10 \mathrm{~min}$. The baseline end-tidal carbon dioxide $\left(\mathrm{ETCO}_{2}\right)$, inspired minimum carbon dioxide $\left(\mathrm{ImCO}_{2}\right), \mathrm{RR}$, mean arterial pressure (MAP), and $\mathrm{SpO}_{2}$ were measured.

The amount of FGF was reduced step-by-step by $0.5 \mathrm{~L} / \mathrm{min}$ every $5 \mathrm{~min}$, waiting for $\mathrm{ImCO}_{2}$ to be regularly maintained for at least $60 \mathrm{sec}$; then $\mathrm{ETCO}_{2}, \mathrm{ImCO}_{2}, \mathrm{RR}, \mathrm{MAP}$, and $\mathrm{SpO}_{2}$ values were recorded at each step until rebreathing occurred $\left(\mathrm{ImCO}_{2}>0\right)$. FGF was then reduced to $2.5 \mathrm{~L} / \mathrm{min}$ and $\mathrm{ImCO}_{2}$ was recorded.
A

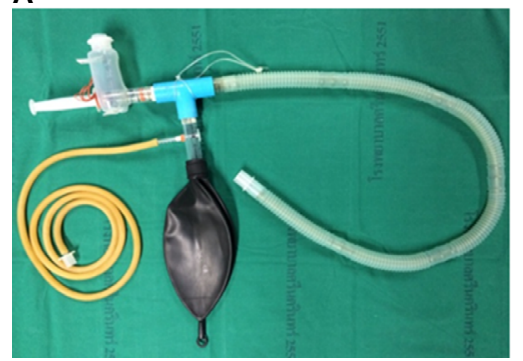

\section{B}

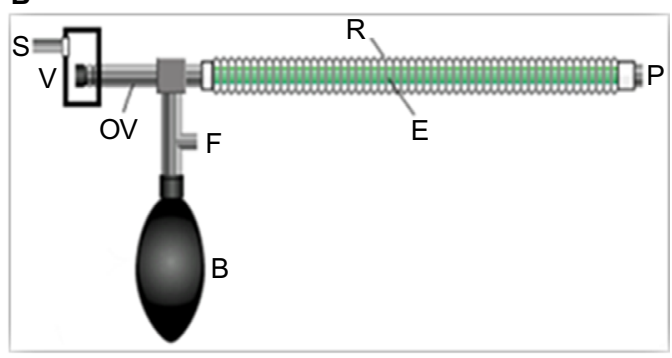

Figure I Lack-Plus circuit: actual circuit (A) and diagram (B).

Abbreviations: $B$, breathing reservoir bag; $E$, inner exhaust tube; $F$, fresh gas inlet; OV, intraluminal one-way valve; $P$, patient; $R$, outer reservoir tube; $S$, scavenging system; $\mathrm{V}$, syringe expiratory valve. 
The anesthetic breathing circuit was switched over. The FGF was switched back to $4 \mathrm{~L} / \mathrm{min}$ for $10 \mathrm{~min}$, after which the procedure was repeated. The minimal FGF before rebreathing occurred and the $\mathrm{ImCO}_{2}$ at a FGF of $2.5 \mathrm{~L} / \mathrm{min}$ were recorded.

All intraoperative and postoperative complications were observed and recorded. The study flow is presented in Figure 2.

\section{Statistical analysis}

A minimum of 20 patients were needed to detect a clinically relevant reduction in FGF of $20 \%$, with a power of 0.90 and a level of significance of $5 \%$. Twenty-four patients were recruited to cover a potential dropout rate of $20 \%$. Randomization was achieved using a computer-generated list (kept in sealed envelopes). Statistical analyses were performed with Statistical Package for the Social Sciences (SPSS) for Windows version 17.0 (SPSS Inc., Chicago, IL, USA). Continuous data were expressed as mean $\pm \mathrm{SD}$ and compared using the paired Student's $t$-test or Mann-Whitney $U$ test where applicable. Categorical data were expressed by number (\%), and comparison was made by chi-square test. A $p$-value $<0.05$ was considered statistically significant.

\section{Results}

Twenty-four patients fulfilled the entry criteria and were enrolled in the study. Both groups (LP-L and L-LP) were comparable with respect to age, sex, BMI, ASA physical status, and type of operation (Table 1).

Table I Demographic and clinical data of the patients in the LP-L and L-LP groups

\begin{tabular}{|c|c|c|c|}
\hline Variables & $\begin{array}{l}\text { LP-L } \\
(n=\mid 2)\end{array}$ & $\begin{array}{l}\text { L-LP } \\
(n=\mid 2)\end{array}$ & $p$-value \\
\hline Age (year) & $38.5 \pm 13.9$ & $36.5 \pm 15.2$ & 0.741 \\
\hline Sex: male & $8(66.7)$ & $4(33.3)$ & 0.102 \\
\hline $\mathrm{BMI}\left(\mathrm{kg} / \mathrm{m}^{2}\right)$ & $23.6 \pm 3.3$ & $22.3 \pm 2.7$ & 0.301 \\
\hline Body temperature $\left({ }^{\circ} \mathrm{C}\right)$ & $36.9 \pm 0.5$ & $36.8 \pm 0.5$ & 0.990 \\
\hline \multicolumn{4}{|l|}{ ASA classification } \\
\hline I & $8(66.7)$ & $9(75)$ & 0.653 \\
\hline II & $4(33.3)$ & $3(25)$ & \\
\hline \multicolumn{4}{|l|}{ Operation } \\
\hline Orthopedics & $3(25)$ & $2(16.7)$ & 0.879 \\
\hline ENT & $8(66.7)$ & $9(75)$ & \\
\hline Plastic & I (8.3) & I (8.3) & \\
\hline
\end{tabular}

Note: Values are presented as mean \pm SD or number (\%).

Abbreviations: LP-L, Lack-Plus followed by Lack's circuit; L-LP, Lack's followed by Lack-Plus circuit; BMI, body mass index; ASA, American Society of Anesthesiologists; ENT, ear, nose, throat; SD, standard deviation.

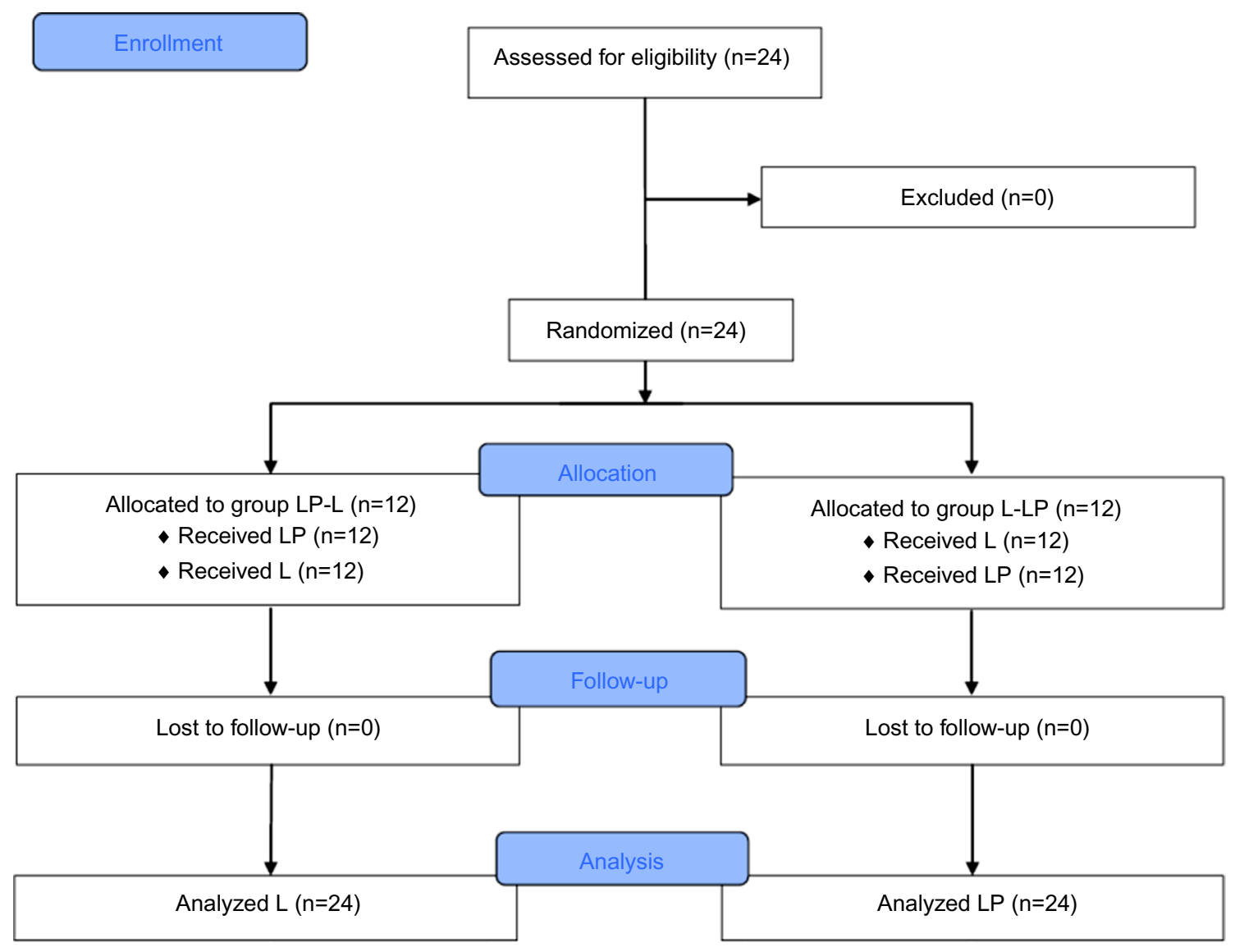

Figure 2 CONSORT flow diagram of the study.

Abbreviations: LP-L, Lack-Plus followed by Lack's circuit; L-LP, Lack's followed by Lack-Plus circuit; LP, Lack-Plus group; L, Lack group; CONSORT, Consolidated Standards of Reporting Trials. 
Table $2 \mathrm{FGF}, \mathrm{ETCO}, \mathrm{RR}, \mathrm{MAP}$, and $\mathrm{SpO}_{2}$ at point of rebreathing $\left(\mathrm{ImCO} \mathrm{m}_{2}>0 \mathrm{mmHg}\right)$

\begin{tabular}{llllll}
\hline Variables & $\mathbf{L}$ & $\mathbf{L P}$ & $\mathbf{M e a n}$ & $\mathbf{9 5 \%} \mathbf{C l}$ & $\mathbf{p}$-value \\
& $(\mathbf{n = 2 4 )}$ & $\mathbf{( n = 2 4 )}$ & difference & \\
\hline FGF $(\mathrm{L} / \mathrm{min})$ & $3.3 \pm 0.5$ & $2.7 \pm 0.8$ & -0.63 & $-0.86,-0.40$ & $<0.001$ \\
$\mathrm{ETCO}_{2}(\mathrm{mmHg})$ & $44.8 \pm 8.1$ & $46.9 \pm 7.9$ & 2.09 & $0.29,3.89$ & 0.025 \\
$\mathrm{RR}(\mathrm{tpm})$ & $11.9 \pm 1.6$ & $11.5 \pm 1.2$ & -0.36 & $-1.10,0.38$ & 0.321 \\
$\mathrm{MAP}(\mathrm{mmHg})$ & $72.9 \pm 11.3$ & $73.4 \pm 8.0$ & 0.50 & $-2.79,3.79$ & 0.755 \\
$\mathrm{SPO}_{2}(\%)$ & $99.2 \pm 1.4$ & $99.2 \pm 1.3$ & 0.00 & $-0.13,0.13$ & 1.000 \\
\hline
\end{tabular}

Note: Values are presented as mean \pm SD.

Abbreviations: FGF, fresh gas flow; $\mathrm{ETCO}_{2}$, end-tidal carbon dioxide; RR, respiratory rate; MAP, mean arterial pressure; SpO ${ }_{2}$, oxygen saturation; ImCO, inspired minimum carbon dioxide; L, Lack group; LP, Lack-Plus group; CI, confidence interval; SD, standard deviation.

Table $3 \mathrm{ImCO}_{2}, \mathrm{ETCO}_{2}$, RR, MAP, and $\mathrm{SpO}_{2}$ at FGF $2.5 \mathrm{~L} / \mathrm{min}$

\begin{tabular}{|c|c|c|c|c|c|}
\hline Variables & $\begin{array}{l}L \\
(n=24)\end{array}$ & $\begin{array}{l}\text { LP } \\
(n=24)\end{array}$ & $\begin{array}{l}\text { Mean } \\
\text { difference }\end{array}$ & $95 \% \mathrm{Cl}$ & $p$-value \\
\hline $\mathrm{ImCO}_{2}(\mathrm{mmHg})$ & $4.2 \pm 2.6$ & $1.5 \pm 2.0$ & -2.68 & $-3.60,-1.76$ & $<0.001$ \\
\hline $\mathrm{ETCO}_{2}(\mathrm{mmHg})$ & $46.5 \pm 8.4$ & $47.0 \pm 7.8$ & 0.50 & $-1.02,2.02$ & 0.504 \\
\hline $\mathrm{RR}(\mathrm{tpm})$ & $11.8 \pm 1.3$ & $11.2 \pm 1.3$ & -0.63 & $-1.22,-0.04$ & 0.036 \\
\hline $\operatorname{MAP}(\mathrm{mmHg})$ & $76.2 \pm 11.9$ & $72.3 \pm 10.1$ & -3.86 & $-8.21,0.48$ & 0.079 \\
\hline $\mathrm{SpO}_{2}(\%)$ & $99.4 \pm 1.1$ & $99.4 \pm 1.1$ & 0.00 & $-0.23,0.23$ & 1.000 \\
\hline
\end{tabular}

Note: Values are presented as mean \pm SD.

Abbreviations: $\mathrm{ImCO}_{2}$, inspired minimum carbon dioxide; $\mathrm{ETCO}_{2}$, end-tidal carbon dioxide; $\mathrm{RR}$, respiratory rate; $\mathrm{MAP}$, mean arterial pressure; SpO , oxygen saturation; FGF, fresh gas flow; L, Lack group; LP, Lack-Plus group; Cl, confidence interval; SD, standard deviation.

\section{Primary outcome}

The mean minimal FGF at the point of rebreathing was significantly lower in the Lack-Plus group than in the Lack group $(p<0.001)$ (Table 2$)$. The $\mathrm{ETCO}_{2}$ level was significantly higher in the Lack-Plus group, and the FGF requirement was decreased by $18.7 \%$ for no rebreathing. The mean RR, arterial pressure, and $\mathrm{SpO}_{2}$ value between the groups were not significantly different.

\section{Secondary outcome}

The mean $\mathrm{ImCO}_{2}$ at the FGF of $2.5 \mathrm{~L} / \mathrm{min}$ was significantly lower in the Lack-Plus group than in the Lack group $(p<0.001)$ (Table 3$)$. There was no statistically significant difference between the groups vis-à-vis $\mathrm{ETCO}_{2}, \mathrm{MAP}$, and $\mathrm{SpO}_{2}$. The RR was statistically different but was within normal clinical range (11.8 and $11.2 \mathrm{tpm}$ ). No incidence of complications was observed during perioperative period.

\section{Discussion}

Among non-absorber anesthetic breathing circuits, the Magill's, Lack's, and Bain's circuits are commonly used during general anesthesia for spontaneous respiration in adult patients. Humphrey ${ }^{1}$ demonstrated that the Lack's circuit had the lowest $\mathrm{ImCO}_{2}$ and $\mathrm{ETCO}_{2}$ compared to the Magill's and Bain's circuits, by using a FGF of $70 \mathrm{~mL} / \mathrm{kg} / \mathrm{min}$.
Additionally, the respective FGF requirement in the Lack's, Magill's, and Bain's circuits that caused rebreathing was 51, 73, and $153 \mathrm{~mL} / \mathrm{kg} / \mathrm{min}$, respectively. The Lack's circuit, therefore, appears superior in performance to the Magill's and Bain's circuits for spontaneous respiration in adults, economical use of FGF, convenient exhaust valve, and easy scavenging facilities.

The Lack-Plus circuit - a modification of the Lack's - was invented by Theerapongpakdee ${ }^{2,3}$ for spontaneous breathing anesthesia in adults. Theerapongpakdee devised the LackPlus circuit using materials readily available in the operating room (Figure 1).

The intraluminal one-way valve - situated on the expiratory limb of the non-absorber breathing system - was used in the new enclosed anesthetic circuit such as the enclosed afferent reservoir (EAR), ${ }^{4}$ baby EAR, ${ }^{5,6}$ and displacement afferent reservoir (DAR) systems. The advantage of such a position was more effective prevention of rebreathing during the inspiration phase.

Our hypothesis is that the Lack-Plus circuit - with the addition of an intraluminal one-way valve - would be more efficient than the Lack's circuit in that it requires less FGF to prevent rebreathing, reduces loss of heat and humidity, and causes less pollution in the operating room.

The minimal FGF at the point of rebreathing for the Lack-Plus circuit in the current report was significantly 
less than for the Lack's circuit $(2.7 \pm 0.8$ and $3.3 \pm 0.5$ $\mathrm{L} / \mathrm{min}$, respectively, $p<0.001)$. This result agrees with Kain and Nunn ${ }^{8,9}$ who demonstrated that the minimal adequate FGF to prevent rebreathing of the Magill's circuit was $3.1-4.6 \mathrm{~L} / \mathrm{min}$. At a FGF of $2.5 \mathrm{~L} / \mathrm{min}$, the $\mathrm{ImCO}_{2}$ of the Lack-Plus circuit was significantly lower than the Lack's circuit (1.5 \pm 2.0 and $4.2 \pm 2.6 \mathrm{mmHg}$ respectively, $p<0.001$ ), demonstrating that the intraluminal one-way valve situated proximal to the APL valve effectively helps to prevent rebreathing.

$\mathrm{ETCO}_{2}$ at the point of rebreathing in both the groups was statistically significant different. Notwithstanding, there were no significant differences in clinical practice owing to the $\mathrm{ETCO}_{2}$ value of both the systems, which were within the normal, clinical, acceptable range (46.9 \pm 7.9 and $44.8 \pm 8.1$ mmHg, respectively, $p=0.025$ ).

\section{Limitations of the study}

Since we reduced FGF at a step of $0.5 \mathrm{~L} / \mathrm{min}$, it might be not absolutely accurate to detect the actual FGF at each end point of the study.

\section{Conclusion}

The Lack-Plus circuit is a modified Lack's circuit (i.e., a modified co-axial Mapleson A), which is a non-carbon dioxide absorber anesthetic circuit with an additional intraluminal one-way valve and a gas scavenging port. It can be used safely, effectively, and requires less FGF than the Lack's circuit in spontaneously breathing anesthetized adults (BMI $\leq 30 \mathrm{~kg} / \mathrm{m}^{2}$ ). The optimal FGF requirement for the Lack-Plus circuit to prevent rebreathing is $2.7 \pm 0.8 \mathrm{~L} / \mathrm{min}$.

\section{Acknowledgments}

This study received support from the Research Affairs Unit, Faculty of Medicine, KKU, Thailand. The authors would like to thank Mr. Bryan Roderick Hamman for assistance with the English language presentation of the manuscript via the Publication Clinic, KKU, Thailand. The abstract of this paper was presented at the annual meeting of Faculty of Medicine, KKU on October 7, 2015. The poster's abstract was published in the supplementation issue of Srinagarind Medical Journal in 2015.

\section{Disclosure}

The authors report no conflicts of interest in this work.

\section{References}

1. Humphrey D. The lack, magill and bain anaesthetic breathing systems: a direct comparison in spontaneously-breathing anaesthetized adults. J R Soc Med. 1982;75:513-524.

2. Theerapongpakdee $\mathrm{S}$. Invention of coaxial Mapleson A circuit by using simple economic material. Thai J Anesthesiol. 1984;11:173-180.

3. Theerapongpakdee S. Carbon dioxide concentration in coaxial Mapleson A circuit. Khon Kaen University Health Sci Center Bullet (annex). 1985;11: 7-9.

4. Miller DM, Miller JC. Enclosed afferent reservoir breathing systems. Description and clinical evaluation. Br J Anaesth. 1988;60:469-475.

5. Theerapongpakdee S, Phanpanusit T, Horatanaruang D, et al. A clinical determination of optimal fresh gas flow in a baby EAR circuit. JMed Assoc Thai. 2009;92:667-671.

6. Theerapongpakdee S, Sathitkarnmanee T, Tribuddharat S, et al. Comparison of minimal fresh gas requirements of baby enclosed afferent reservoir and Jackson Rees anesthetic circuit for general anesthesia in spontaneously breathing children. JMedAssoc Thai. 2014;97:1171-1176.

7. Miller DM. An enclosed efferent afferent reservoir system: the Maxima. Anaesth Intens Care. 1995;23:284-291.

8. Kain ML, Nunn JF. Fresh gas flow and re-breathing in the Magill circuit with spontaneous respiration. Proc R Soc Med. 1967;60:749-750.

9. Kain ML, Nunn JF. Fresh gas economics of the Magill circuit. Anesthesiology. 1968;29:964-974.
Medical Devices: Evidence and Research

\section{Publish your work in this journal}

Medical Devices: Evidence and Research is an international, peerreviewed, open access journal that focuses on the evidence, technology, research, and expert opinion supporting the use and application of medical devices in the diagnosis, monitoring, treatment and management of clinical conditions and physiological processes. The identification of novel

\section{Dovepress}

devices and optimal use of existing devices which will lead to improved clinical outcomes and more effective patient management and safety is a key feature. The manuscript management system is completely online and includes a quick and fair peer-review system. Visit http://www. dovepress.com/testimonials.php to read real quotes from authors. 